\title{
A INTERDISCIPLINARIDADE NO ENSINO DE ARQUITETURA: ANÁLISE A PARTIR DA DISCIPLINA DE PROJETO ARQUITETÔNICO
}

\author{
Eliana Nunes Ribeiro Batista ${ }^{1}$, Raimunda Abou Gebran ${ }^{2}$ \\ ${ }^{1}$ Mestre em Educação pelo Programa de Pós-Graduação em Educação da Universidade do Oeste Paulista - UNOESTE. Professora do Curso de \\ Arquitetura e Urbanismo da Universidade do Oeste Paulista - UNOESTE, Presidente Prudente, SP. E-mail: elianaribeiro.arq@gmail.com \\ 2 Doutora em Educação pela Universidade Estadual de Campinas - UNICAMP. Professora do Programa de Pós-Graduação em Educação da \\ Universidade do Oeste Paulista - UNOESTE, Presidente Prudente, SP.
}

\section{RESUMO}

O presente artigo é parte de uma pesquisa que teve como objetivo analisar a proposição e o desenvolvimento didático-pedagógico da disciplina Projeto Arquitetônico, como favorecedora da interdisciplinaridade, em um Curso de Graduação em Arquitetura. A pesquisa configurou-se como abordagem qualitativa, caracterizando-se como estudo de caso, e os procedimentos para a coleta de dados foram: entrevistas semiestruturadas com os participantes (alunos, docentes e coordenação) e análise documental (Diretrizes Curriculares para o curso de Graduação em Arquitetura, Projeto Pedagógico e planos de ensino da disciplina). Os dados coletados permitiram o levantamento de cinco categorias de análise, a saber: As intencionalidades e objetivações da disciplina de Projeto Arquitetônico; A transversalidade da disciplina de Projeto Arquitetônico e a interdisciplinaridade; A interdisciplinaridade se concretizando na ação; Aspectos propiciadores e dificultadores; Indicativos e ações para interdisciplinaridade. Os resultados da pesquisa revelaram que o ensino da disciplina pouco propicia a interdisciplinaridade; os documentos analisados (PPC e planos de ensino das disciplinas) não apresentam propostas que de fato propiciem ações interdisciplinares; os professores não estabelecem troca de informações e parcerias para a concretização da interdisciplinaridade. Portanto, é necessária a reestruturação da disciplina, bem como a reformulação do PPC e dos planos de ensino das disciplinas para que os conteúdos se relacionem e sejam conduzidos para a disciplina de Projeto. Acredita-se que esse estudo poderá suscitar discussões e reflexões sobre o ensino de Arquitetura e a interdisciplinaridade, a fim de contribuir para a formação dos futuros arquitetos.

Palavras-chave: Interdisciplinaridade. Ensino de Arquitetura. Projeto Arquitetônico. Ação Docente.

\section{THE INTERDISCIPLINARY TEACHING OF ARCHITECTURE: ANALYSIS FROM THE DISCIPLINE OF ARCHITECTURAL PROJECT}

\begin{abstract}
This article is part of a research entitled and the main objective is to analyze the proposal and the pedagogical didactic development of the subject Architectural Project, as a supporter of the interdisciplinary program, in an Architecture Graduation. The research was developed as a qualitative approach, characterizing itself as a study of cases, being used on data collecting, semi-structured interviews of the people involved (students, teachers and course coordinator) and documentary analysis (Curricular Guidelines for the Undergraduate Degree Course in Architecture, Pedagogical Project of the Course and teaching plans for the discipline). The data which had been collected allowed the creation of five categories of analysis: The intentions and objectives of the discipline of Architectural Design; The transversality and interdisciplinarity on the discipline of Architectural Design; Interdisciplinarity materializing in action; Challenges and difficulties faced by students, teachers and coordination; Actions for interdisciplinarity. The results of the research revealed that: teaching a discipline does not foster interdisciplinarity; The documents analyzed (PPC and teaching plans of the subject) do not present proposals that surely provide interdisciplinary actions in the course; Teachers do not establish exchange of information and partnerships. In order to make interdisciplinarity effective in the course, it is necessary to restructure the discipline so that it is set in an interdisciplinary way, as well as the reformulation of the PPC and the teaching plans of the disciplines so that the contents are related and lead to the discipline project. Besides that, it requires the involvement, communication and integration of teachers and students. It is believed that this study
\end{abstract}


may lead discussions and reflections on the teaching of Architecture and interdisciplinarity, in order to contribute to the formation of future architects.

Keywords: Interdisciplinarity. Architecture Teaching. Architectural project. Teaching action.

\section{INTRODUÇÃO}

A disciplina de Projeto Arquitetônico tem um papel importante para a formação do aluno de Arquitetura e Urbanismo uma vez que se faz presente na grade curricular do curso do 1 응 5 은 ano, sendo que é nela que se realiza a síntese dos conhecimentos adquiridos durante o curso. Por este motivo, surgiu a necessidade de uma pesquisa mais pontual sobre a interdisciplinaridade no ensino de projeto, com o intuito de contribuir para o melhor desempenho discente no curso e para a elaboração de projetos arquitetônicos realizados pelos futuros arquitetos.

A interdisciplinaridade é um termo que possui diferentes interpretações, porém em todas as abordagens sobre o tema está implícita uma nova mudança de atitude do professor e do aluno, a fim de estabelecer uma unidade de pensamento para atingir o conhecimento globalizado. Para Japiassu (1976), a interdisciplinaridade se refere às relações entre as disciplinas e o conteúdo estudado. As relações mencionadas pelo autor são compreendidas como forma de trabalhar o ensino em sala de aula, quando um mesmo tema é discutido e abordado em diferentes disciplinas. Desta forma, é possível compreender as partes e estabelecer relações entre diferentes áreas do conhecimento com o intuito de superar o isolamento entre os conteúdos e as disciplinas.

Para Fazenda (1995), a interdisciplinaridade ocorre por meio de parceira e conscientização e depende mais do encontro entre as pessoas envolvidas (sujeitos) do que entre as disciplinas. A prática interdisciplinar é estabelecida no momento em que existem ações que propiciam diálogos entre as disciplinas e entre os sujeitos das ações, ou seja, ela se desenvolve num trabalho de parceria e reflexão. Quando o ensino é desenvolvido por meios de ações interdisciplinares existe a superação de uma visão fragmentada e linear da produção de conhecimento.

No que diz respeito ao ensino de Arquitetura, os estudos de Lawson (2011), Kowaltowski et al. (2011) revelam que a formação profissional do arquiteto exige uma perspectiva interdisciplinar, uma vez que as competências do profissional arquiteto são de múltiplas procedências e sua formação e atuação profissional envolvem o conhecimento de políticas públicas, arte, técnica, história, entre outros.

No que se refere à fundamentação legal que trata da formação do arquiteto, as Diretrizes Curriculares Nacionais do Curso de Graduação em Arquitetura e Urbanismo (2010) também indicam que as instituições devem proporcionar ao estudante, formas de realização da interdisciplinaridade e modos de integração entre as disciplinas teóricas e práticas.

Diante disso, algumas questões nortearam a presente pesquisa, tais como:

- A disciplina de Projeto propicia ações interdisciplinares ao longo do curso?

- Como a interdisciplinaridade se revela na ação dos docentes do curso e, em especial, dos docentes responsáveis pela disciplina de Projeto Arquitetônico?

- Como os alunos percebem e vivenciam as relações entre as disciplinas?

O objetivo geral da pesquisa foi analisar a proposição e o desenvolvimento didáticopedagógico da disciplina de Projeto Arquitetônico, como favorecedora da interdisciplinaridade em um Curso de Graduação em Arquitetura, de uma instituição privada localizada no Oeste Paulista.

Acreditamos que os resultados atingidos com esta pesquisa possam favorecer a organização de uma metodologia interdisciplinar para o curso. A pesquisa poderá contribuir com as discussões e reflexões no âmbito dos processos de ensino e aprendizagem e colaborar para o ensino de Arquitetura.

\section{REFERENCIAL TEÓRICO}

A interdisciplinaridade surgiu no Brasil no final da década de 60 e teve como precursores Fazenda (2001) e Japiassú (1979), com estudos que abriram caminhos para outros autores pesquisadores de propostas metodológicas interdisciplinares. 
Japiassu (1976) foi o primeiro estudioso no Brasil a discutir a interdisciplinaridade no campo da epistemologia, influenciado pela obra de Georges Gusdorf. A primeira produção de Japiassu, lançada em um livro, faz uma reflexão sobre estratégias, abordando os principais questionamentos, reflexões e conceitos sobre interdisciplinaridade, de acordo com resultado das experiências que realizava na época. "Tudo isso, no contexto de uma epistemologia das ciências humanas, às voltas com suas "crises" e com seus impasses metodológicos. A resolução dessas crises coincide pelo menos em parte, com os objetivos a que se propõe o método interdisciplinar". (JAPIASSU, 1976, p. 53).

No que diz respeito à metodologia interdisciplinar, Japiassu (1976) afirma que está diretamente relacionada com a solução de como um projeto pode ser colocado em prática. Preocupa-se também em analisar as condições de um projeto interdisciplinar, estudando as relações e inter-relações de forma muito similar com Gusdorf (1987). Ambos os pesquisadores afirmam que devem ser tomados cuidados básicos na constituição de uma equipe multidisciplinar, haja vista que há a necessidade de se estabelecer como comunicação clara e concisa por meio de "conceitos-chave". Pode-se afirmar que esses aspectos são essenciais para o desenvolvimento interdisciplinar.

De acordo com Fazenda (2011), a metodologia do processo interdisciplinar envolve integração. Esta integração ocorre no momento específico de organização de estudos dos conteúdos e das disciplinas, e para que o trabalho interdisciplinar seja consolidado deve existir interação, incluindo co-participação, reciprocidade e mutualidade. Portanto, a integração pode ser considerada como uma forma de operacionalização e um meio para alcançar a interdisciplinaridade.

Para discutir a interdisciplinaridade, é importante enfatizar as dimensões conceituais sobre o tema. Sendo assim, dada a importância destas dimensões conceituais, Pombo (2008) apresenta a definição da palavra e o sufixo.

Haveria, portanto, uma espécie de um contínuo de desenvolvimento. Entre uma coisa que é de menos - a simples justaposição e qualquer coisa que é demais - a ultrapassagem e a fusão - a interdisciplinaridade designaria o espaço intermédio, a posição intercalar. O sufixo inter estaria lá justamente para apontar essa situação. (POMBO, 2008, p. 6).

Para o autor, quando se trata a interdisciplinaridade a partir do estudo da palavra disciplina e seu sufixo, chega-se a um conceito em que se busca a inter-relação, comunicação e interação entre diferentes disciplinas. A palavra interdisciplinar é formada pela união do prefixo "inter", que tem o sentido de "entre". A junção de ambas as palavras caracterizam a relação de conteúdos entre duas ou mais disciplinas.

Para Fazenda (1995), o que caracteriza a interdisciplinaridade é o encontro entre os seres, ou seja, depende mais do encontro entre as pessoas envolvidas (sujeitos) do que entre as disciplinas. Ela ocorre por meio do sistema de parceria e da conscientização da importância e da plenitude do conhecimento, além das interações sociais. Esta caracterização da interdisciplinaridade corrobora as definições de Luck (2001), ao defini-la como sendo:
[...] o processo de integração e engajamento de educadores, num trabalho conjunto, de interação das disciplinas do currículo escolar entre si e com a realidade, de modo a superar a fragmentação do ensino, objetivando a formação integral dos alunos, a fim de que exerçam a cidadania, mediante uma visão global de mundo e com capacidade para enfrentar os problemas complexos, amplos e globais da realidade. (LUCK, 2001, p. 64).

Portanto, a interdisciplinaridade corresponde a uma nova consciência da realidade e a um novo modo de refletir e pensar o ensino, baseados no ato de troca do conhecimento, de reciprocidade entre áreas diferentes, objetivando a construção de novos conhecimentos por meio da busca de resolução para os problemas, das novas reflexões e questionamentos para a elucidação de uma nova realidade. 
Para Japiassu (1976), a busca de interação entre duas ou mais disciplinas é a característica central da interdisciplinaridade, pois consiste no fato de que ela incorpora os resultados de várias disciplinas. Além disso, ela previne o fracionamento, ao propor as interconexões disciplinares. Destaca também a necessidade de uma profunda revisão de pensamento, que deve caminhar no sentido do diálogo e da troca e da interação entre diversas áreas do saber. reconhecemos diante de um empreendimento interdisciplinar todas às vezes em que ele conseguir incorporar os resultados de várias especialidades, que tomar de empréstimo a outras disciplinas certos instrumentos e técnicas metodológicos, fazendo uso dos esquemas conceituais e das análises que se encontram nos diversos ramos do saber, a fim de fazê-los integrarem e convergirem, depois de terem sido comparados e julgados. Donde podermos dizer que o papel específico da atividade interdisciplinar consiste, primordialmente, em lançar uma ponte para religar as fronteiras que haviam sido estabelecidas anteriormente entre as disciplinas com o objetivo preciso de assegurar a cada uma seu caráter propriamente positivo, segundo modos particulares e com resultados específicos. (JAPIASSU, 1976, p.75).

O autor destaca uma forma de trabalho para os professores, na qual se propõe um tema com abordagens em diferentes disciplinas, reforçando que é necessário compreender, entender as partes de ligação entre as diversas áreas de conhecimento, fazer análises e considerações, com o objetivo de unir e criar pontes para restabelecer as relações entre as disciplinas.
Desta forma é possível interagir e ultrapassar a fragmentação do pensamento (JAPIASSU, 1976).

\section{METODOLOGIA DA PESQUISA}

Com o objetivo de atingir o melhor resultado para a pesquisa, a metodologia escolhida foi realizada assumindo uma abordagem de pesquisa do tipo qualitativa, configurando-se como estudo de caso, sendo utilizados como procedimentos para a coleta de dados, entrevistas semiestruturadas e análise documental.

Consideramos os sujeitos da pesquisa como sendo todos os atores envolvidos no contexto real da experiência: seis estudantes do 10 ao 50 ano do Curso de Arquitetura da Instituição em estudo (dois alunos do início, dois alunos do período intermediário e dois alunos que estão no final do curso), três professores que lecionam disciplinas complementares do 1 음 ao 5은 ano (um do início, um do meio e um do final do curso); três professores que lecionam as disciplinas de Projeto Arquitetônico do 10 ao 5o ano (um do início, um do meio, um do final do curso), e um coordenador do curso. Os critérios de seleção dos participantes foram aleatórios, de acordo com a disponibilidade e interesse de docentes e discentes em participar da pesquisa.

Em processo realizamos, inicialmente, uma pesquisa bibliográfica para fundamentar teoricamente e contextualizar o assunto abordado. Um segundo procedimento constituiuse na análise documental que, segundo Lüdke e André (2014), tem como objetivo identificar informações obtidas a partir de documentos. Os documentos analisados na pesquisa foram: Diretrizes Curriculares Nacionais para o curso de Arquitetura e Urbanismo, Projeto Pedagógico do Curso de Arquitetura e Urbanismo, Planos de ensino e ementários das disciplinas de Projeto Arquitetônico semestrais que acontecem do 1을 ao 5 o ano do curso.

As entrevistas foram desenvolvidas a partir de um roteiro pré-determinado, que combinaram perguntas abertas e fechadas, procurando identificar respostas para as questões que norteiam o trabalho, a fim de alcançar o melhor resultado na obtenção dos dados coletados.

Para o desenvolvimento das análises dos dados, servimo-nos dos direcionamentos de Bardin (2011), que explica que a análise do conteúdo procura conhecer aquilo que está por trás do significado das palavras. Seguindo o 
direcionamento do referencial teórico de Bardin (2011) e Triviños (1987), o processo de exploração para análise do material coletado na pesquisa, iniciou-se com a leitura dos dados para organização dos recortes. Em seguida, os recortes foram organizados por aproximação de itens de interesse conforme os objetivos da pesquisa, resultando em cinco categorias temáticas que permitiram a análise dos significados dos dados da pesquisa.

A pesquisa foi apreciada e aprovada pelo Comitê de Ética da UNOESTE no processo número: 1.452.189, da Plataforma Brasil.

\section{RESULTADOS}

Para as análises dos dados, consideramos o Projeto Pedagógico do Curso (PPC), os Planos de Ensino das disciplinas, os questionários e entrevistas com professores, alunos e coordenação do curso. Apresentamos as análises dos dados, organizadas em cinco categorias que emergiram do próprio material de pesquisa.

\section{As intencionalidades e objetivações da disciplina Projeto Arquitetônico}

Nessa categoria buscamos analisar, a partir das Diretrizes Curriculares para o Curso de Graduação em Arquitetura (Resolução 02/2012), do Projeto Pedagógico do Curso (PCC) e dos planos de ensino das disciplinas, quais as intencionalidades e objetivações da disciplina Projeto Arquitetônico, em especial no que diz respeito ao seu caráter interdisciplinar.

O curso propõe a formação do arquiteto que tenha a capacidade de pesquisar, projetar e executar serviços da área de arquitetura e construção civil. Para atingir tais objetivos, a grade curricular dá ênfase nas áreas de Projeto de Arquitetura, Urbanismo e Paisagismo. É explicito também como objetivo, segundo Universidade do Oeste Paulista, (2012, p. 25), "Propiciar através de integração interdisciplinar uma visão sistêmica, de modo que o futuro profissional tenha ideia integrada do seu trabalho".

Verificamos que a interdisciplinaridade é mencionada na proposta pedagógica como algo que pretende ser alcançado, porém não é especificado como acontecem as ações e nem é identificada uma proposta metodológica de caráter interdisciplinar que envolva a disciplina de Projeto.

No documento em estudo, é explicito que o PPC foi baseado nas Diretrizes Curriculares
Nacionais dos cursos de Graduação em Arquitetura e Urbanismo (BRASIL, 2010), que explicita:

Art. 3o O projeto
pedagógico do curso de
graduação em Arquitetura
e Urbanismo, além da
clara concepção do curso,
com suas peculiaridades,
seu currículo pleno e sua
operacionalização, deverá
incluir, sem prejuízos de
outros, os seguintes
aspectos: ing
I - objetivos gerais do
curso, contextualizado às
suas inserções
institucional, política,
geográfica e social;
II - condições
objetivas de oferta e a
vocação do curso;
III - formas de
realização da
interdisciplinaridade;
IV - modos de
integração entre teoria e
prática;
V - formas de avaliação do
ensino e da aprendizagem;
(BRASIL, 2010, p. 01).

Fica claro nas diretrizes curriculares que é indispensável constar no PPC como se procedem as formas de realizações da interdisciplinaridade, bem como as formas de integração entre a teoria e a prática. Entre outros itens do documento, verificamos também que a proposta pedagógica do curso deve garantir a formação de profissionais generalistas e demonstrar claramente as atividades que garantem o desenvolvimento das competências e habilidades que buscam atingir o objetivo do perfil profissional desejado.

Nesse sentido, evidenciamos que o projeto do curso não atende às orientações das diretrizes, uma vez que não consta de forma clara como a interdisciplinaridade acontece e nem as ações necessárias para que ela se concretize. Essa ausência traz prejuízos para o desenvolvimento de competências e habilidades voltadas para a apropriação de um conhecimento globalizado, o que pode implicar em comprometimento na formação do perfil profissional desejado.

Nos planos de ensino das disciplinas de Projeto, não há indicativos de intencionalidade 
interdisciplinar, assim como não evidenciamos proposição metodológica que caracterize uma ação pedagógica interdisciplinar.

\section{A transversalidade da disciplina de Projeto Arquitetônico e a interdisciplinaridade}

Na segunda categoria são destacadas, a partir das falas dos sujeitos, as percepções sobre a disciplina Projeto no que se refere ao seu caráter transversal no curso, ou seja, como se situa verticalmente (ao longo do curso) e horizontalmente (no mesmo termo). Apresentamos as análises das falas que mencionam sobre tentativas de alguns professores e disciplinas em estabelecer a interdisciplinaridade no mesmo termo, evidenciando também as percepções dos alunos sobre o ensino interdisciplinar.

A fala da coordenadora revela que existe uma tentativa da transversalidade em algumas disciplinas, porém isso acontece em alguns momentos do curso de forma pontual, sem que se configure um processo. A coordenadora revela que o trabalho é desenvolvido com apenas duas disciplinas, como evidenciado abaixo:

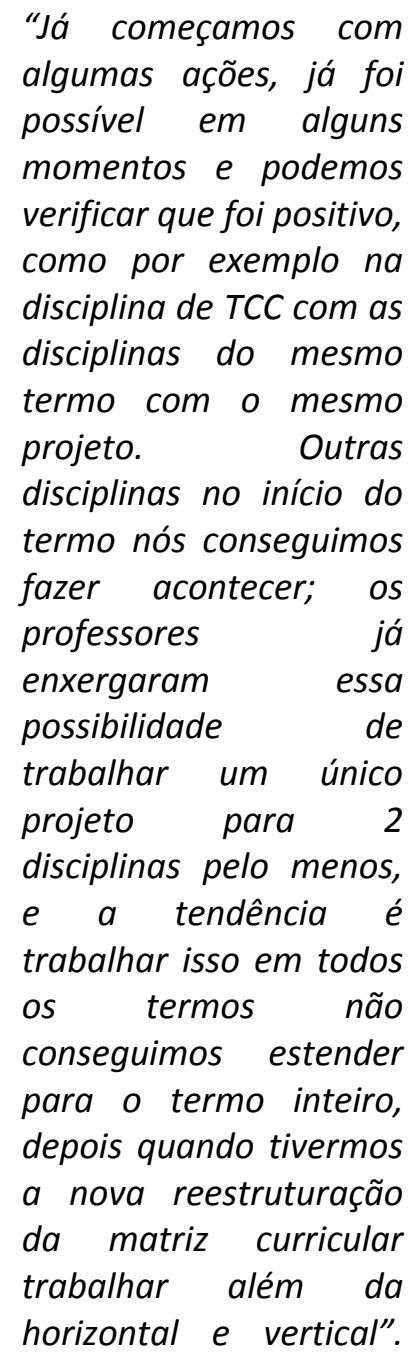

(Informação verbal, Coordenadora, 2017).

As declarações da coordenadora são ratificadas pela docente $\mathrm{P} 6$, ao afirmar que considera muito importante a prática interdisciplinar e sempre que consegue estabelece trocas com professores das disciplinas de Projetos do 50 termo. Destaca uma experiência com a docente $P 2$, relatando que ambas se unem e trabalham o desenvolvimento de atividades em uma mesma área física de estudo, atividade que nem sempre é possível de ser realizada no curso.

"Quando eu consigo faço
trocas com a professora do
5 o termo, eu dou
centralidades no 5o temo
(Urbanismo II), e ela (a
P2), está lecionando
Projeto Institucional no
mesmo termo ao mesmo
tempo, então nos unimos,
eu faço análise urbanística
e ela faz análise do lote,
uma coisa tá
complementando a outra".
(Informação verbal, P6,
2017).

A Professora P2, que leciona disciplinas de Projeto Arquitetônico I, Desempenho Térmico e Luminotécnica, afirma que existe uma tentativa por parte dela em desenvolver uma prática interdisciplinar, visto que suas disciplinas já possuem relações de conteúdo, mas não consegue fazer com todas elas porque desconhece o conteúdo que é desenvolvido pelos demais docentes, corroborado sua fala: "Eu tento porque eu já dou algumas disciplinas que se relacionam, mas não consigo fazer com todas porque eu não sei o que o professor está dando". (Informação verbal, P2, 2017).

Podemos perceber relações entre a fala da P5 e P2, uma vez que ambas tentam estabelecer relações interdisciplinares com as demais disciplinas e professores do mesmo termo, de forma esporádica. Porém, isso não se concretiza de maneira formalizada porque nem todos os professores estabelecem trocas de informações. Essa análise vai na contramão das proposições de Fazenda (2009) que, ao definir a interdisciplinaridade como união de disciplinas, refere-se à formatação da estrutura curricular e 
articulação de conteúdos propostos e desenvolvidos.

No que se refere ás falas dos estudantes, percebemos que para dois dos entrevistados a interdisciplinaridade está subtendida, não é explícita na ação dos professores:

"Essa interdisciplinaridade, nós temos essa que é meio escondida, que é toda a experiência do professor de projeto mas eu acho que falta muito o professor proporcionar uma experiência diferente ao aluno". (Informação verbal, A2, 2017).

"Eu acho que não é um hábito porque eu não percebi que isso é tão evidente no curso, eu acho que talvez esteja muito escondido, não fica evidente". (Informação verbal, A6, 2017).

Um dos alunos relata que as disciplinas de exatas parecem não possuir proximidades, ou seja, “(...) As matérias exatas não percebo, parecem mais afastadas" (Informação verbal, A3, 2017), enquanto que para outro aluno não existe intencionalidade e motivação por parte dos professores para que a interdisciplinaridade aconteça, afirmando que "Eu não consigo ver muita motivação e sim uma necessidade; sem perceber nós acabamos usando informações das outras disciplinas. (Informação verbal, A6, 2017).

$O$ fato de os professores não deixarem claro a interdisciplinaridade, não planejarem e não desenvolverem atividades que estabelecem relações e trocas entre a maioria das disciplinas da grade curricular, conduz-nos ao entendimento de que realmente o ensino interdisciplinar não acontece no curso.

\section{A interdisciplinaridade se concretizando na ação}

Foram diagnosticadas nas falas dos sujeitos entrevistados, algumas ações que os alunos precisam desenvolver de acordo a elaboração de um Projeto Arquitetônico. Além disso, foram detectadas ações que partem das iniciativas dos professores para o desenvolvimento de atividades. Para os alunos, a interdisciplinaridade acontece quando se inicia o projeto, especificamente no momento das reflexões e surgimento do partido arquitetônico, bem como no desenvolvimento projetual, conforme as falas:

"Sim, quando eu faço os
croquis e começo a pensar
no projeto, quando eu
penso no conceito e
partido". (Informação
verbal, A5, 2017).

"Eu acho que é o momento que você tem que juntar tudo o conhecimento para projetar (...), eu consigo perceber as relações, se você vai desenvolver um projeto você precisa pensar em insolação, então você vai buscar o conhecimento da disciplina de insolação, você precisa fazer uma releitura de um fato histórico, então buscamos na disciplina de História, eu acredito que engloba o conhecimento que $o$ aluno adquire em todas as disciplinas $e$ aplica em projeto". (Informação verbal, A1, 2017).

De acordo com Kowaltowski et al. (2011), independente da metodologia projetual adotada pela instituição ou pelo docente responsável pela disciplina, os estudos sobre o processo de projeto revelam que este possui característica interdisciplinar.

Por exemplo, em Arquitetura o projeto de um edifício envolve o conhecimento da área de engenharia estrutural, mecânica, elétrica, hidráulica e dos confortos térmicos, acústico, funcional e luminoso. E ainda há o envolvimento da estética em fatores como volumes, forma, material e cor. (KOWALTOWSKI et al., 2011, p. 152).

Para os autores, é importante e necessário que o docente e o aluno estabeleçam relações interdisciplinares entre os conteúdos estudados e prática de projeto, tendo em vista 
que as fases do projeto são complexas e exigem domínio de conhecimentos sobre diversas áreas e disciplinas.

Com relação aos docentes, a maioria dos professores afirmaram que já realizaram tentativas em desenvolver algum tipo de atividade interdisciplinar, não obtendo muito sucesso porque depende do envolvimento das partes interessadas. Ressaltamos a fala da docente $P 1$, quando relata que, durante 0 desenvolvimento das atividades, de acordo com a dificuldade do aluno, ela encaminha para outros professores para sanar as dúvidas específicas do conteúdo. No entanto, não é percebido nenhuma iniciativa de atividades entre eles, ou seja, não é desenvolvido um trabalho em conjunto:

\begin{abstract}
"Eu tento (..) eu tentei já fazer isso algumas vezes lá na Instituição. Algumas foram insucessos, em outras, algumas partes deram certo". (Informação verbal, $P 3,2017)$.

"Hoje eu estou mandando voltar para os professores das disciplinas. Se chega o momento de fazer um projeto, ele não sabe fazer a representação gráfica, eu peço para voltar com o professor. Se o aluno não sabe topografia, eu ensino, mas eu peço para eles procurarem 0 professor da disciplina de topografia". (Informação verbal, $P 1,2016)$.
\end{abstract}

Verificamos nas falas dos envolvidos, algumas iniciativas que buscam práticas interdisciplinares, porém as mesmas não vão ao encontro das proposições de Fazenda (2001), que destaca que a interdisciplinaridade depende de atitude que promova ações interdisciplinares, parcerias dos atores envolvidos e a totalidade do conhecimento embasados no fazer pedagógico.

\section{Aspectos propiciadores e dificultadores}

De acordo com as análises, um dos aspectos propiciadores consiste na disponibilidade dos alunos para a prática interdisciplinar. Em suas falas, percebemos que são dispostos a se envolverem com atividades que permitam as interações, relações e dinâmicas interdisciplinares. Notamos também uma preocupação da coordenação do curso em busca dessa tentativa, pois, durante a entrevista apresentou consciência de que é necessário promover ações para a concretização de ações interdisciplinares, ressaltando a necessidade de repensar e promover mudanças na matriz curricular, o que exigirá, como aponta Fazenda (2010), trocas, estudos, reflexões e disposição para a mudança por parte dos docentes das diferentes áreas e disciplinas do curso.

"Temos falado muito sobre $a$ interdisciplinaridade $e$ pedido nas reuniões com docentes, mas enxergamos que temos que mudar a matriz curricular para conseguir atingir esse objetivo". (Informação verbal, Coordenadora, 2017).

A fala da coordenadora direciona-se para as posições de duas docentes (P5 e P6). A primeira menciona o interesse pela criação de um Projeto integrador e demonstra visão sobre a importância do trabalho coletivo e do processo de ensino e aprendizagem globalizado. A segunda apresenta em sua fala a preocupação com o ensino interdisciplinar e destaca que ele deveria acontecer entre todas as disciplinas do curso. Os aspectos propiciadores enfatizados nas falas das professoras dizem respeito à conscientização dos trabalhos interdisciplinares para o ensino de Arquitetura e à predisposição dos professores para o ensino integrado.

"O meu trabalho só existe
se for somado com o
trabalho do outro, porque
o nosso objetivo não é só
dar uma aula, é fazer com
que o aluno tenha as
relações do todo (...). Essa
perspectiva de trabalhar o
projeto integrador é uma
maneira interessante de
promover
interdisciplinaridade, eu
acredito que pode ser um
caminho muito
interessante (...)".
(Informação verbal, P5,
2017). na no
"Nar verdade
interdisciplinaridade no
projeto arquitetônico
deveria ser cobrada em


todos os termos e em todas as disciplinas". (Informação verbal, P6, 2017).

As transcrições das entrevistas vão ao encontro de Fazenda (2001), no que diz respeito à disposição para o trabalho interdisciplinar. Para a autora, o trabalho interdisciplinar exige interação em forma de um regime que inclui coparticipação, reciprocidade, disposição dos sujeitos na busca do ensino globalizado.

De acordo com depoimentos dos alunos, chamou-nos muita atenção alguns aspectos que dificultam a possibilidade do trabalho interdisciplinar. Uma das reclamações dos alunos é a ausência das relações entre a prática projetual e a prática da construção. De acordo com os relatos abaixo:

"Essa relação de tentar enxergar alguns elementos que estão relacionados com o que o professor fala e tentar enxergar com a prática, eu tenho dificuldade de enxergar $e$ também de entender alguns termos(...) Eu acho que o principal é você conseguir relacionar a ideia que temos para desenvolver o projeto, com a maneira com que você vai executar aquilo". (Informação verbal, A1, 2017).

"Às vezes ficamos vendo só a teoria, teoria e talvez o aluno nunca viu de fato uma parede levantando por exemplo". (Informação verbal, A2, 2017).

Outras dificuldades destacadas pelos alunos estão relacionadas ao momento do desenvolvimento do Projeto Arquitetônico, revelando percepções do conhecimento fragmentado e dificuldades em fazer as junções de conteúdo, conforme relatos abaixo:

"Nós alunos de
Arquitetura cometemos
muitos erros de projeto,
principalmente na parte
de cálculo, temos
dificuldade de entender
como aplicar no projeto".

(Informação verbal, A2, 2017).

"A maior dificuldade sempre é com o conteúdo mais técnico da área, o pessoal tem muita dificuldade, desenvolver parte gráfica, desenho". (Informação verbal, A4, 2017).

O aprofundamento da análise dos dados permitiu-nos perceber que, além da fragmentação do conteúdo e a dificuldade de se estabelecer relações, também há falta de comunicação e de parceria entre os professores. Além disso, alguns alunos apontam a falta de evidência da interdisciplinaridade na disciplina de Projeto, como se segue:

"Não é que o professor não tenha conhecimento mas acho que é uma questão de parceira talvez deles". (Informação verbal, A1, 2017)

"Eu acho que talvez não seja uma dificuldade, mas talvez não seja hábito de alguns professores(...) não é um hábito porque eu não percebi que isso é tão evidente no curso, eu acho que talvez esteja muito escondido, não fica evidente". (Informação verbal, A6, 2017).

$\mathrm{Na}$ análise das respostas, vimos que, de maneira geral, a grande lacuna é a falta de comunicação entre os professores e destes com os alunos, para que processos interdisciplinares sejam desencadeados, conforme explicitados nas declarações dos docentes abaixo:

"Acho que a primeira é ter um interlocutor, a primeira dificuldade(...) É alguém que quer dialogar sobre isso. Acho que é a primeira dificuldade (...) se o aluno não ver que os professores se dispõe a tal, eles vão ter dificuldades. Se eles têm professores que se dispõem a discutir e a construir essa interdisciplinaridade, ele 
vai ver como é muito mais fácil". (Informação verbal, P3, 2017).

"Embora eu ache necessário, eu tenho muita dificuldade porque, a gente tem um conteúdo para terminar (...) $E$ aí você fica desesperado pra terminar o seu (...) eu indico onde eles vão usar, mas eu não consigo criar ainda atividades onde eu amarre uma disciplina com a outra, porque mais uma vez, pra isso nós precisaríamos ter uma reunião, sentar todo mundo junto". (Informação verbal, P4), 2017.

Fazenda (1995) reafirma que interdisciplinaridade vai além das relações sociais, ela acontece por meio do sistema de parceria e da conscientização da importância e da plenitude do conhecimento. Os professores apontam ainda que um dos grandes problemas é a incompatibilidade de horários disponíveis para conversas e estabelecer relações interpessoais com os demais docentes. Os docentes enfatizam:

"Se eu sinto dificuldades? Muitas. Acho que a primeira dificuldade é ter um interlocutor, (...). É alguém que queira dialogar sobre isso. Acho que é a primeira dificuldade". (Informação verbal, P3, 2017).

“(...) tempo pra fazer isso. Como falei, a gente tem 44 horas-aula e as minhas 44 hs não coincidem com a de outros professores. Às vezes eu tenho aula nos períodos tarde e noite; outros professores tem aula no período da manhã e da tarde. Porém no período da tarde os professores estão dando aula, entendeu? A maior dificuldade é não ter esse horário comum pra fazer isso, para fazer reunião, para organizar a interdisciplinaridade". (Informação verbal, P4, 2017).

Com relação à falta de tempo para que o corpo docente se comunique, a fala da coordenação ratifica a posição dos docentes e destaca a necessidade de serem criados espaços institucionais para que esse processo se desenvolva.

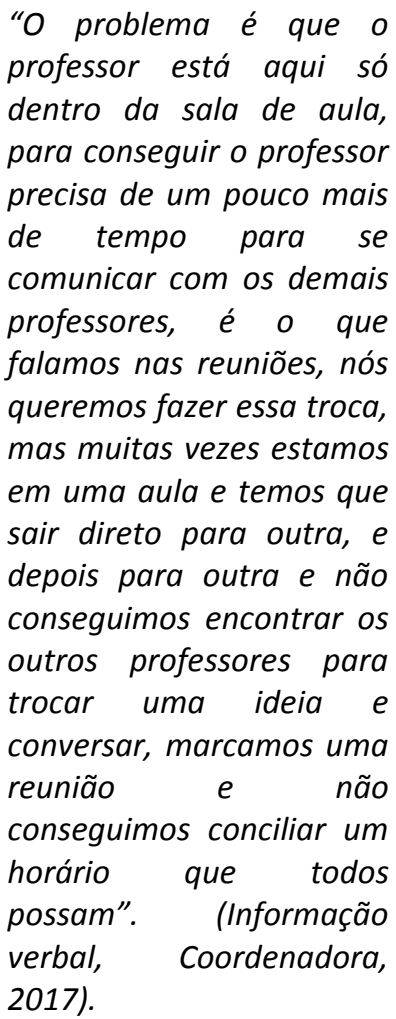

Estes aspectos revelam atitudes pouco significativas na atuação profissional docente. Fazenda (1991) destaca que o professor precisa ser humilde e possuir princípio e compromisso com a educação, ter condições de reconhecer os limites do conhecimento fragmentado, eliminando as barreiras entre as pessoas e permitindo o diálogo.

Neste sentido, percebemos que a organização institucional vigente possui ausência de ações interdisciplinares. As atitudes dos professores e as definições das ações no PPC do curso estão distantes de serem caracterizadas como proposições da interdisciplinaridade. As explanações não representam parcerias dos sujeitos em prol do ensino articulado. Os elementos facilitadores identificados são praticamente inexistentes pela falta de uma proposição pedagógica consistente, que favoreça 
ações e processos que se encaminhem na direção da interdisciplinaridade.

\section{Indicativos e ações de interdisciplinaridade}

Nesta categoria discutimos as perspectivas e projeções para o curso, em especial no tocante à interdisciplinaridade. Constituem-se em indicativos diagnosticados nas falas dos participantes da pesquisa que podem contribuir para melhoria do processo de ensino e aprendizagem do curso.

A coordenação destaca que existe por parte do coletivo o interesse para uma reestruturação da matriz curricular, o que poderia favorecer processos e ações interdisciplinares, em especial a partir da disciplina de Projetos.

"Na nova reestruturação
da matriz curricular
pretendemos trabalhar a
interdisciplinaridade na
horizontal e na vertical
(...), é extremamente
necessário fazer o aluno
entender que tudo está
interligado tanto na
vertical e horizontal".
(Informação verbal,
Coordenadora, 2017).

A fala da coordenadora vai ao encontro do posicionamento de um dos alunos, que sugere a reestruturação curricular do curso, alinhando os conteúdos para que realmente sejam trabalhados e convergidos na disciplina.

"Talvez uma
reestruturação da grade
seria melhor(..)eu acho
que o termo poderia ser
interdisciplinar, deveria ser
mais amarrado não só
pelo professor arquiteto
mais por todos os
professores". (Informação
verbal, A2, 2017).

As proposições indicam a necessidade de reestruturações e revisões que implicariam em mudanças conceituais, teóricas e metodológicas. De acordo com Morin (2005), a nossa forma de pensar fragmentada, racionalizada, precisa ser revista e deve ser capaz de conciliar pensamentos conflitivos que são opostos e de nos ensinar a dialogar, ou seja, a pensar em religar pensamentos. Neste sentido, compreendemos que a reforma da matriz curricular pode propiciar também uma reforma do pensamento.

Os professores apontaram que é necessário maior comunicação e intencionalidade dos discentes para o desenvolvimento de processos interdisciplinares, que envolveriam especialmente reuniões pedagógicas para alinhamento dos conteúdos e troca de informações.

"Ter mais reuniões para os professores saberem o que está sendo dado em cada disciplina, para que possamos desenvolver ações como por exemplo, a criação de um projeto integrador (...) que relacione todas as disciplinas". (Informação verbal, P2, 2017).

“(..) eu acho que é uma mudança de postura que precisamos ter". (Informação verbal, P5, 2017).

Outros professores (P2, P3 e P6) apontaram a criação de um projeto integrador como já acontece em cursos de Arquitetura de outras instituições. Indicam ainda ações menores que envolvam atividades interdisciplinares, como por exemplo: conteúdos que possam ser trabalhados e avaliados simultaneamente por duas ou mais disciplinas, considerando o excesso de atividades e trabalhos do curso. A docente P2 sugere um melhor aproveitamento de estudos desenvolvidos nas disciplinas complementares, incorporando-os em um projeto integrador.

"Exemplo, usar uma
residência que é
desenvolvida em projeto
arquitetônico, usa-la para
estudar e aplicar a
insolação e iluminação,
usar o mesmo lote da
residência e estudar em
urbanismo, usar em
sistemas estruturais,
desenho técnico e em
todas as disciplinas".
(Informação verbal, P2,
2017).

"A primeira coisa eu acho que é trabalhar um projeto integrador porque o aluno 
vai entender o porquê ele está aplicando

determinado

conhecimento, $e$ as disciplinas de cada semestre acaba tendo um valor maior para ele, além disso outras ações menores que envolvam atividades

interdisciplinares, um conteúdo que é trabalhado parte em uma disciplina $e$ parte em outra também para que ele não tenha vários trabalhos que ocupem muito tempo deles (...), desta forma eles conseguem se envolver de maneira maior nos trabalhos. (Informação verbal, P5, 2017).

Esses indicativos apontados pelos professores da pesquisa, entre eles a criação de um Ateliê Vertical, vão de encontro às ações interdisciplinares explanadas no aporte teórico. Nesse sentido, sugerimos a criação de um projeto integrado de Arquitetura e Urbanismo, como já é concretizado na FAU/UFRJ, ou um ateliê integrado, ora horizontal, ora vertical como acontece no curso da UFRN, ou a criação de um Ateliê vertical como da Escola da Cidade de São Paulo.

Com o objetivo de contribuir com indicativos mais próximos da realidade do curso, detectamos dentro da própria Instituição em estudo, uma disciplina chamada Projeto Integrador de Disciplinas (PID), criada e institucionalizada em 2012 nos Cursos Superiores de Tecnologia da Faculdade de Informática, a íntegra do documento Regulamento PID (2016), consta nos anexos desta pesquisa.

É importante ressaltar que os indicativos apontados por docentes e alunos podem se constituir como ponto de partida para que ações interdisciplinares possam ser viabilizadas. Contudo, como afirma Fazenda (1991), depende muito da disposição e do envolvimento de cada indivíduo, que se dispõe ao diálogo, às novas parcerias, às reflexões e às novas ações, ou seja, da atitude dos sujeitos envolvidos. A interdisciplinaridade é uma vontade de uma escolha, do desejo de criar, integrar, desafiar, transformar.

\section{CONSIDERAÇÕES FINAIS}

A trajetória da pesquisa permitiu um aprofundamento sobre a questão da interdisciplinaridade e sobre o ensino de Arquitetura, em especial sobre a disciplina de Projeto. Frente aos problemas que são propostos e que surgem no desenvolvimento do Projeto Arquitetônico, o aluno precisa integrar conteúdos dos diversos componentes curriculares e ser capaz de realizar reflexões e ações. Para que isso se concretize, é preciso que o aluno adquira o conhecimento globalizado e estabeleça relações de conteúdo.

Contudo, no curso em estudo, a pesquisa revelou que as intencionalidades e objetivações propostas no projeto pedagógico não consideram a prática interdisciplinar como ação a ser viabilizada, uma vez que não há menções sobre essa questão entre as disciplinas e não é apresentada uma ideia clara e objetiva da construção desse processo. Na mesma linha de análise, verificamos que os planos de ensino da disciplina de Projeto, ministrada do 10 ao 5o ano do curso, não explicitam proposição de ações que favoreçam relações e articulações da disciplina com as demais disciplinas do curso, quer no sentido horizontal, quer no sentido vertical, apesar de se considerar que essa disciplina apresenta um caráter integrador.

Da mesma forma, verificamos nas falas dos participantes da pesquisa, em especial dos professores e da coordenação, que não acontecem parcerias e diálogos entre os professores e não ocorrem encontros entre os docentes que possam desencadear o desenvolvimento de propostas interdisciplinares.

Isso também se revela na fala dos alunos que percebem a falta de estímulo, envolvimento e comunicação dos professores para a realização de atividades interdisciplinaridades. Indicaram, ainda, que a ausência de ações dos docentes que favoreçam o estabelecimento de relações de conteúdo das diferentes disciplinas, implica em sérias dificuldades momento da elaboração do Projeto Arquitetônico. Apontam que sentem falta de relações entre a teoria e a prática, assim como da vivência da Arquitetura fora do ambiente da faculdade, a fim de propiciar contribuições para o exercício profissional, do ponto de vista da materialidade da área.

Frente às dificuldades detectadas nas análises, os resultados levam-nos a refletir também sobre a ausência de mais envolvimento e da institucionalização de uma estrutura 
organizada e sistematizada que, com a contribuição de todo o corpo docente, poderia nortear as ações e resultados de efetivos trabalhos interdisciplinares. Faz-se necessário o desenvolvimento de iniciativas por parte da instituição e da coordenação pedagógica para a estruturação da disciplina a partir das definições do processo de ensino interdisciplinar.

Entendemos que é necessária a criação de uma estrutura que estabeleça conexão entre todos os componentes curriculares, uma reestruturação da grade de ensino, alinhando os conteúdos que serão abordados para que realmente sejam trabalhados e convergidos, direcionando-os para a atividade da disciplina de Projeto.

É relevante ressaltarmos que as discussões acerca do tema precisam ser aprofundadas, os dados e conclusões desta pesquisa precisam ser discutidos e divulgados junto ao corpo docente, coordenação e administração pedagógica da Instituição. Os resultados que foram obtidos podem ser subsídios para a construção de uma estrutura mais adequada às necessidades do curso. Desta forma, acreditamos que a pesquisa poderá contribuir nas discussões e reflexões sobre o ensino de Arquitetura, colaborando para melhoria dos processos de ensino e aprendizagem do aluno.

\section{REFERÊNCIAS}

BARDIN, L. Análise de conteúdo. Lisboa: Edições 70, 2011.

BRASIL. MEC-CNE/CES no 2, de 17 de junho de 2010. Institui as Diretrizes Curriculares Nacionais do curso de graduação em Arquitetura e Urbanismo, alterando dispositivos da Resolução CNE/CES no6/2006. Diário Oficial [da] República Federativa do Brasil, Brasília, 18 jun. 2010. Seção 1, p. 37-38.

FAZENDA, I. C. A. Interdisciplinaridade: um projeto em parceria. São Paulo: Loyola, 1991.

FAZENDA, I. C. A. Interdisciplinaridade: um projeto em parceria. 3. ed. São Paulo: Loyola, 1995.

FAZENDA, I. C. A. Interdisciplinaridade: história, teoria e pesquisa. 7. ed. Campinas: Papiros, 2001.
FAZENDA, I. C. A. (org.). 0 que é interdisciplinaridade? São Paulo: Cortez, 2009.

JAPIASSU, H. Interdisciplinaridade e patologia do saber. Rio de Janeiro: Imago, 1976.

KOWALTOWSKI, D. C. K. C. et al. O processo de projeto em Arquitetura. São Paulo: Oficina de Textos, 2011.

LAWSON, B. Como os arquitetos e designers pensam. 4. ed. São Paulo: Oficina de Textos, 2011.

LUCK, H. Pedagogia da interdisciplinaridade: fundamentos teórico-metodológicos. Petrópolis: Vozes, 2001.

LUDKE, M.; ANDRÉ, M. E. D. A. Pesquisa em educação: abordagens qualitativas.

Rio de Janeiro: Pedagógica e Universitária, 2014.

POMBO, O. Epistemologia da interdisciplinaridade. Revista do Centro de Educação e Letras, v. 10, p. 9-40, 2008.

TRIVIÑOS, A. N. S. Introdução à pesquisa em ciências sociais: a pesquisa qualitativa em educação. São Paulo: Atlas, 1987.

UNIVERSIDADE DO OESTE PAULISTA. Projeto Político Pedagógico: Resolução 2. Presidente Prudente: Unoeste, 2012.

Recebido para publicação em: 17/08/2017

Revisado em: 29/08/2017

Aceito em: 02/09/2017 